American Journal of Applied Sciences 9 (5): 633-640, 2012

ISSN 1546-9239

(C) 2012 Science Publications

\title{
Organizational Support and Achievement Motivation in Leadership Role of Extension Agents
}

\author{
${ }^{1}$ Roya Karami, ${ }^{1}$ Maimunah Ismail, ${ }^{1}$ Zoharah Binti Omar, \\ ${ }^{1}$ Nor Wahiza Binti Abdul Wahat and ${ }^{2}$ Mohammad Badsar \\ ${ }^{1}$ Department of Professional Development and Continuing Education, \\ Faculty of Educational Studies, \\ University Putra Malaysia, 43400 Serdang, Selangor, Malaysia \\ ${ }^{2}$ Institute of Social Science Studies, \\ University Putra Malaysia, 43400 Serdang, Selangor, Malaysia
}

\begin{abstract}
Problem statement: This study argues for the importance of organizational non work supports along with work support for achievement motivation in leadership role of extension agents which has mostly been silent in past studies. Further, although there are studies that showed a positive relationship between organizational support and performance but no study so far has investigated the relationships between organizational support in terms of work and non work supports with three dimensions of achievement motivation including aspiration, mastery and salience. Approach: The study data were collected using questionnaire from 201 extension agents from the Ministry of Jihad-eAgriculture in Iran. The data were analyzed using AMOS software. Results: The results showed that organizational work supports significantly related to aspiration and mastery dimensions of achievement motivation while organizational non work supports significantly related to aspiration and salience dimensions of achievement motivation. Conclusion: The study is useful for extension organizations to convey the favorable treatment including work and non work supports to motivate the agents to achieve leadership role.
\end{abstract}

Key words: Achievement motivation, leadership role, organizational work support, organizational non work support, extension agents, psychological functions, activating behavior

\section{INTRODUCTION}

Literatures on achievement motivation are weak in two fundamental aspects. First, definition of the achievement concept, second, understanding of how achievement should be conceptualized (Elliot and Dweck, 2005). Competence as a primary motivation that assists individuals to adapt oneself to the environment was proposed as the conceptual center of the achievement that could flourish the weakness of achievement studies. The motivational analysis of competence could explain the ways in which individual behaviors are energizing, directing and regulating persistence of behavior (Alderman, 2007). Thus, the present research concentrates on leadership role, proposed as a foundation of key competency of extension agents in conceptualizing achievement motivation. Further, achievement motivation is considered to have three dimensions including aspiration, mastery and salience which are in accordance with the studies of Farmer (1997) and London and Noe (1997) and they are further consistent with constituents of motivation including direction, effort and persistence (Armstrong, 2006). Career aspiration is a dimension of internal career that fundamentally emerges from an individual, which in turn influences one's value, norms and beliefs (Ismail and Ramly, 2011). It is in agreement with the results of a study by Suthar and Tarmizi (2010). Mastery motivation refers to "the tendency of persons to choose difficult challenging tasks rather than easy tasks and to keep struggling to master the task once they have started" (Farmer, 1985). Salience refers to the value people put on the work role, which can be modified during their life (Sweenet, 2004).

There are many factors influencing achievement motivation, one of which is organizational support. Although there are studies that showed a positive relationship between organizational support and performance but no study so far has investigated the

Corresponding Author: Maimunah Ismail, Department of Professional Development and Continuing Education, 
relationships of organizational support in terms of work and non work support and the three dimensions of achievement motivation.

More precisely, the present research refers to extension organization supports defined as perception of employees regarding the organizational concern for their well-being and values their contributions (Chow et al., 2006; Eisenbergera et al., 1985; Ferris et al., 2009), through two types of work and non-work supports. Organization work support refers to the environment that supports the work goal structure attainment along with professionalism, development opportunities and meritocracy (Chow et al., 2006; London and Noe, 1997). Organization non-work support refers to family friendly environment that desires to achieve a balance between work and family goals in which taking time out from career for family reasons do not reflect a lack of career commitment. Thus, family-supportive environments refer to a situation in which flextime, part-time work and onsite daycare are available (Lapierre et al., 2008; Ogden et al., 2006). The importance of organizational non work support is close to the study results of Azril et al. (2010) who found individual and family aspect as the highest contributor to work performance of Malaysian agricultural extension agents. According to organizational support theory, perceived organizational support influenced the employee's emotional connection. Further, the extent to which perceived organizational support increases, work effort of workers for meeting organizational goals and as a result their commitment to the organization will be increased (Eisenbergera et al., 1985). High levels of perceived organizational support generate sense of responsibility to pay back the helpfulness of organization which will be shown through extra effort role behavior (Eisenbergera et al., 1985; Hochwarter et al., 2003).

This research combines London and Noe's (1997) career motivation theory and perceived organizational support theory by Eisenbergera et al. (1985), aims to investigate the relationships of work and non work organizational support with three dimensions of achievement motivation (aspiration, mastery and salience). Also using London and Noe's (1997) theory it is hypothesized that aspiration as the first construct of achievement motivation affects mastery and consequently these two constructs affect salience.

Based on the above reviews a research framework is developed as indicated in Fig. 1 we therefore hypothesize that:

H1: There is a significant path among three dimensions of achievement motivation in which aspiration significantly influences mastery and mastery significantly influences salience

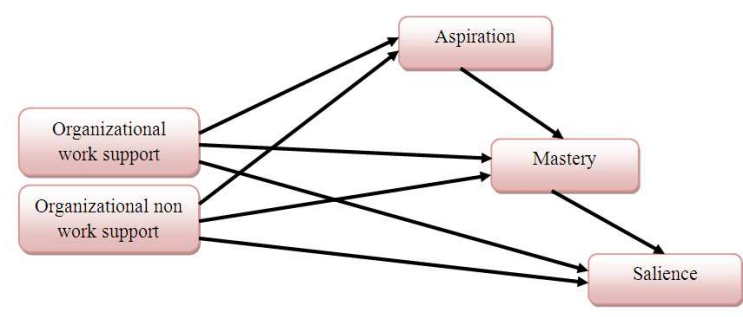

Fig. 1: The research framework

$\mathrm{H} 2$ : There is a relationship between organizational work support and three dimensions of achievement motivation in leadership role that consists of aspiration, mastery and salience

H3: There is a relationship between organizational non work support and three dimensions of achievement motivation in leadership role that consists of aspiration, mastery and salience

\section{MATERIALS AND METHODS}

The study was conducted among extension agents whose role is to lead clients in the community to bring about their development and that of society following an appropriate approach in democratic ways (Chauhan, 2007). The respondents of this study were extension agents of Jihad-e-Agriculture organizations of Kermanshah and Tehran provinces in Iran. A random cluster sampling was conducted to determine the study sample in which from 32 Jihad-e-Agriculture organizations, two were randomly selected as the main clusters of the study. Then all of the extension workers of those provinces including those working in counties or centers were considered as research respondents. Although the number of sample size was previously decided based on the population number, scholars who use Structural Equation Modeling (SEM) mostly discuss the importance of determining sample size based on the number of variables and the complexity of the framework. According to Kline (2008) and Byrne (2001) a sample size of less than 100 cases may be too small, between 150-200 cases is a better minimum, but perhaps even 200 case is insufficient to analyze more complex models, which require the estimation of more parameters. Thus the number of study's sample by considering the number of variables and complexity of research framework considered as 250 . A questionnaire was prepared as the instrument of the study.

The questionnaire was prepared in Persian, which is the original language of the respondents. Thus to check the content and face validity of the scales which was originally in English, translation and back translation was performed. A person highly competent 
in both Persian and English was chosen to translate the measurement from English to Persian. A different person with the same characteristics was chosen to translate the Persian version back into English. Through the comparison of the first English version with the second one, the researcher corrected the inconsistencies. After the back translation, another Iranian subject matter specialist was consulted to improve the face validity of the instrument.

To assess the internal consistency of the data, a pilot study was conducted in the Administration of Jihad-eAgriculture in Bukan County from Azarbayejan Gharbi province. The results indicated that all variables showed acceptable value of Cronbach's alpha. Questionnaires were distributed to respondents by using 'drop-pick' procedures and postal questionnaires. A total of 201 from 250 questionnaires were collected.

The measurement of the study variables are as follow: Aspiration is measured by the coping version of career aspiration scale (cited in Leal, 2006) that was translated to Persian adapted in Karami et al. (2009; 2011). The edited version of the Work and Family Orientation Questionnaire (WOFO) designed by Helmreich Spence in 1978 cited in Leal (2006) was used in this study to measure the mastery motivation. The latest version of salience scale developed by Farmer (1997) was used to assess the respondents salience toward achievement motivation in leadership role. The scale of Perceived Organizational Support cited in (Hochwarter et al., 2003) was used in this study. Hochwarter et al. (2003) used eight items of (Eisenbergera et al., 1985) scale that loaded highest in the original study factor analysis. Also five items were added by the researcher to measure organizational work and non work support.

Table 1: Demographic and professional profile of respondents $(n=303)$

\begin{tabular}{lrc}
\hline \multicolumn{2}{c}{ Frequency } & Percentage \\
\hline Gender & 160 & \\
Male & 41 & 79.6 \\
Female & 40.4 \\
Age (career stage) Mean=41.31 years & \\
$>24$ & 12 & 6.0 \\
$25-44$ & 102 & 50.7 \\
$45-65$ & 87 & 43.3 \\
$<65$ & - & - \\
Educational qualification & & \\
Under diploma & 1 & 0.5 \\
Diploma & 19 & 9.5 \\
Bachelor & 142 & 70.6 \\
Master & 38 & 18.9 \\
PhD & 1 & 0.5 \\
Work experience (Mean=16.17 years) & \\
$>5$ & 37 & 18.4 \\
$5-10$ & 32 & 15.9 \\
$11-15$ & 28 & 13.9 \\
$16-20$ & 30 & 14.9 \\
$21-25$ & 35 & 17.4 \\
$<26$ & 39 & 19.4 \\
\hline
\end{tabular}

Profile of the respondents: A general profile of the respondent's individual characteristics, which consists of gender, age, educational qualification work experience, is presented in Table 1. The results show that around one-fifth $(20.4 \%)$ of the respondents are female and $79.6 \%$ are male. The respondents' average age is 41.31 years old. The majority $(70.6 \%)$ of respondents have a Bachelor of Science degree while $10.0 \%$ of respondents are with under Bachelor of Science degree (diploma certificate and under diploma) and $19.4 \%$ hold an upper level degree. The cumulative percentage of extension agents with work experience less than 15 years $(48.2 \%)$ is remarkable and is close to their means of work experience which is around 16 years.

\section{RESULTS}

To answer the study's inferential objectives, two stages of analyses were conducted as general stages in using the Structural Equation Modeling (SEM). The first stage was about developing and assessing the measurement model, the second stage was about specifying and assessing the structural model.

The measurement model: To verify that the measurement items written to reflect the unobserved constructs do so in a reliable manner, the measurement model was defined by specifying the items of each scale. Since the initial measurement model failed to meet the required Goodness Of Fit (GOF) indices in the confirmatory test of model, several solutions such as investigations on factor loadings and modification indices to remove poor items were estimated and tested. The adequacy of factor loadings was assessed according to the rule by Hair et al. (2010) that judges the size of factor loading higher than 0.5 as a criterion to determine the construct validity of measurement. Thus, some items eliminated and final measurement model was obtained. The confirmed items and their corresponded factor loading are presented in Table 2 .

Further, the assessment of measurement model's GOF indices show that the measurement model presents a relatively good fit between the data and the proposed model. $\chi^{2}(340)=485.775, \quad \mathrm{p}=0.000$ $\chi^{2} / \mathrm{DF}=1.429 ; \mathrm{GFI}=0.859, \mathrm{CFI}=0.959$, TLI $=0.954$, IFI $=0.959$, RMSEA $=0.046$. Thus, it could be interpreted that CFI, TLI IFI significantly pass their cutoff value (0.9). In addition, the RMSEA falls between the recommended range of acceptability (between 0.030.08). Thus, the measurement model meets the requirement of four indices, which according to Hair et al. (2010) if three to four indices meet the requirement, it would be sufficient to claim for a good model fit. 
Am. J. Applied Sci., 9 (5): 633-640, 2012

Table 2: The results of CFA for measurement model

\begin{tabular}{|c|c|c|c|}
\hline Variables & Factor loading & AVE & Construct reliability \\
\hline \multicolumn{4}{|l|}{ Organizational non work support } \\
\hline Item 1: My organization really cares about my well-being. & 0.698 & 0.652 & 0.848 \\
\hline \multirow{2}{*}{\multicolumn{4}{|c|}{$\begin{array}{l}\text { Item 3: Flexible or modified work schedules are available } \\
\text { in my organization }\end{array}$}} \\
\hline & 0.882 & & \\
\hline \multicolumn{4}{|l|}{ Item 4. My organization is willing to help me when } \\
\hline I need a special favor & 0.831 & & \\
\hline \multicolumn{4}{|l|}{ Organizational work support } \\
\hline Item 1: My organization cares about my opinion. & 0.749 & & \\
\hline \multicolumn{4}{|l|}{ Item 2: Freedom to make important work-related decisions are } \\
\hline Item 4: My organization would forgive an honest mistake on my part. & 0.799 & 0.674 & 0.925 \\
\hline $\begin{array}{l}\text { Item 5: There are opportunities for advancement in my organization } \\
\text { for achieving leadership role }\end{array}$ & 0.837 & & \\
\hline $\begin{array}{l}\text { Item 6: There are effective development options or resources available } \\
\text { that can help me improve my career skills }\end{array}$ & 0.872 & & \\
\hline $\begin{array}{l}\text { Item 7: The rewards system in my organization is based on the good } \\
\text { performance such as achieving leadership role }\end{array}$ & 0.847 & & \\
\hline \multicolumn{4}{|l|}{ Aspiration } \\
\hline Item1: I hope to become a leader to the client in my career field & 0.774 & & \\
\hline $\begin{array}{l}\text { Item 2: When I am established in my career, I would like to train } \\
\text { others particularly clients }\end{array}$ & 0.821 & & \\
\hline Item4: I hope to move up through any organization I work in & 0.731 & 0.597 & 0.912 \\
\hline \multicolumn{4}{|l|}{ Item 5: I plan on developing as a leader expert to the client } \\
\hline in my career field & 0.710 & & \\
\hline Item 7: I think I would like to pursue graduate training in my & 0.741 & & \\
\hline \multicolumn{4}{|l|}{ Occupational area of interest } \\
\hline Item 8: Attaining leadership status in my career is not that important to me. & 0.845 & & \\
\hline Item 9: I hope to become a leader to the client in my career field & 0.777 & & \\
\hline \multicolumn{4}{|l|}{ Mastery } \\
\hline Item 1: I like to be busy all the time & 0.798 & & \\
\hline \multicolumn{4}{|l|}{ direct it myself than just help out and have someone else organize } \\
\hline Item 4: I prefer to work in situations that require a high level of skill & 0.680 & 0.649 & 0.916 \\
\hline Item 6: Once I undertake a task, I persist & 0.861 & & \\
\hline Item 7: If I am not good at leading clients I would rather & 0.876 & & \\
\hline \\
\hline \multicolumn{4}{|l|}{ Salience } \\
\hline Item 1: I enjoy making plans about leading clients & 0.882 & & \\
\hline $\begin{array}{l}\text { Item 2: To me, the leadership job role to the client is a means } \\
\text { of expressing myself }\end{array}$ & 0.763 & & \\
\hline $\begin{array}{l}\text { Item 3: I would like to have a job role such as leadership } \\
\text { of which I am really proud }\end{array}$ & 0.692 & 0.585 & 0.893 \\
\hline $\begin{array}{l}\text { Item 4: I like to have a job goal such as leadership } \\
\text { role toward which I can work }\end{array}$ & 0.780 & & \\
\hline $\begin{array}{l}\text { Item 6: I would want to move ahead in my occupation, } \\
\text { through acquisition of leadership role }\end{array}$ & 0.664 & & \\
\hline Item 8: I enjoy making plans about leading clients & 0.787 & & \\
\hline
\end{tabular}

The assessment of validity, reliability, normality multicollinearity is now discussed as the basic assumption in measurement model testing. The construct validity was satisfied in this study, in which all the items had high standardized factor loading on their underlying constructs (values ranged from 0.664 0. 882) (Table 2). Moreover, the convergent validity of constructs was assessed based on the Average Variance Extracted (AVE) that the value for all constructs was equal to or exceeded the minimum criterion of 0.50 , indicating that the majority of the variance was explained by the constructs. The construct reliability values for the constructs ranged from 0.848 to .925 exceeded the minimum requirement of 0.7 , ensuring adequate internal consistency.

A critically important assumption in conducting SEM analyses is the necessity of multivariate normality because of using Maximum Likelihood Estimation (Byrne, 2001). According to Schumacker and Lomax (2004) the data may be assumed to be normal if skewness kurtosis are within the range of $-/+1$, or $-/+1.5$ even $-/+2.0$. The result of normality assessment in the measurement model based on the skewness kurtosis criteria falls within the range of $+/-1.0$ which reveals no 
item to be non-normal. Skewness was ranged from 1.043-244 and kurtosis was ranged from -0.962-0.685.

Another key issue that arises when two or more variables are so highly correlated is multicollinearity. The existence of multicollinearity between two variables shows that both represent the same underlying construct (Byrne, 2001). Hair et al. (2010) state that a correlation estimates among the constructs of 0.9 would result in a tolerance value of 0.19 , which shows a possible problem of multicollinearity. However, in the present measurement model the results of the correlation estimates among the constructs ranged from 0.207-0.389 showing no problems of multicollinearity. Further, as indicated in Table 3 all the items on their underlying constructs were significant that represent accuracy of going to the next step as developing the structural model.

The structural equation model: After specification validation of the measurement model, then the structural model was represented by specifying the set of relationships between constructs. The assessment of the structural model focusing on two issues comprising; (a) the overall relative model fit (b) the size, direction and significance of the structural parameter estimates, depicted with one-headed arrows on a path diagram. Figure 2 shows the results of structural model which indicate that the data fit the model by meeting the requirement of four indices: $\chi^{2}(341)=488.917, \mathrm{p}=$
$0.000 \chi 2 / \mathrm{DF}=1.434 ; \mathrm{GFI}=.858, \mathrm{CFI}=0.958, \mathrm{TLI}=$ 0.954, IFI $=0.959$, RMSEA $=0.047$. Further, Table 4 shows the unstandardized and standardized regression weights for the hypothesized paths in the structural model indicated from 8 paths, 6 were significant by the critical ratio test $(> \pm 10.96, \mathrm{p}<0.05)$. The next step is the interpretation of the results in relation to the study hypotheses.

H1: There is a significant path among three dimensions of achievement motivation in which aspiration significantly influence mastery and mastery significantly influence salience.

The results of the structural model (Fig. 2 and Table 4) indicate that there is a significant positive relationship between latent construct of aspiration and mastery $(\beta=0.319$, C.R. $=3.944$, sig $=0.000)$.

Table 3: The correlations estimate between the constructs

\begin{tabular}{|c|c|c|c|c|c|}
\hline Variable & 1 & 2 & 3 & 4 & 5 \\
\hline Aspiration & 1 & & & & \\
\hline Mastery & $0.389 * *$ & 1 & & & \\
\hline Salience & $0.324 * *$ & $0.309^{* *}$ & 1 & & \\
\hline $\begin{array}{l}\text { Organizational } \\
\text { non work support }\end{array}$ & $0.326^{* *}$ & $0.207^{*}$ & $0.355^{* *}$ & 1 & \\
\hline $\begin{array}{l}\text { Organizational } \\
\text { work support }\end{array}$ & $0.291 * *$ & $0.299 * *$ & $0.287 * *$ & $0.277 * *$ & 1 \\
\hline
\end{tabular}

*sig. at .05 level, ** sig. at .01 level

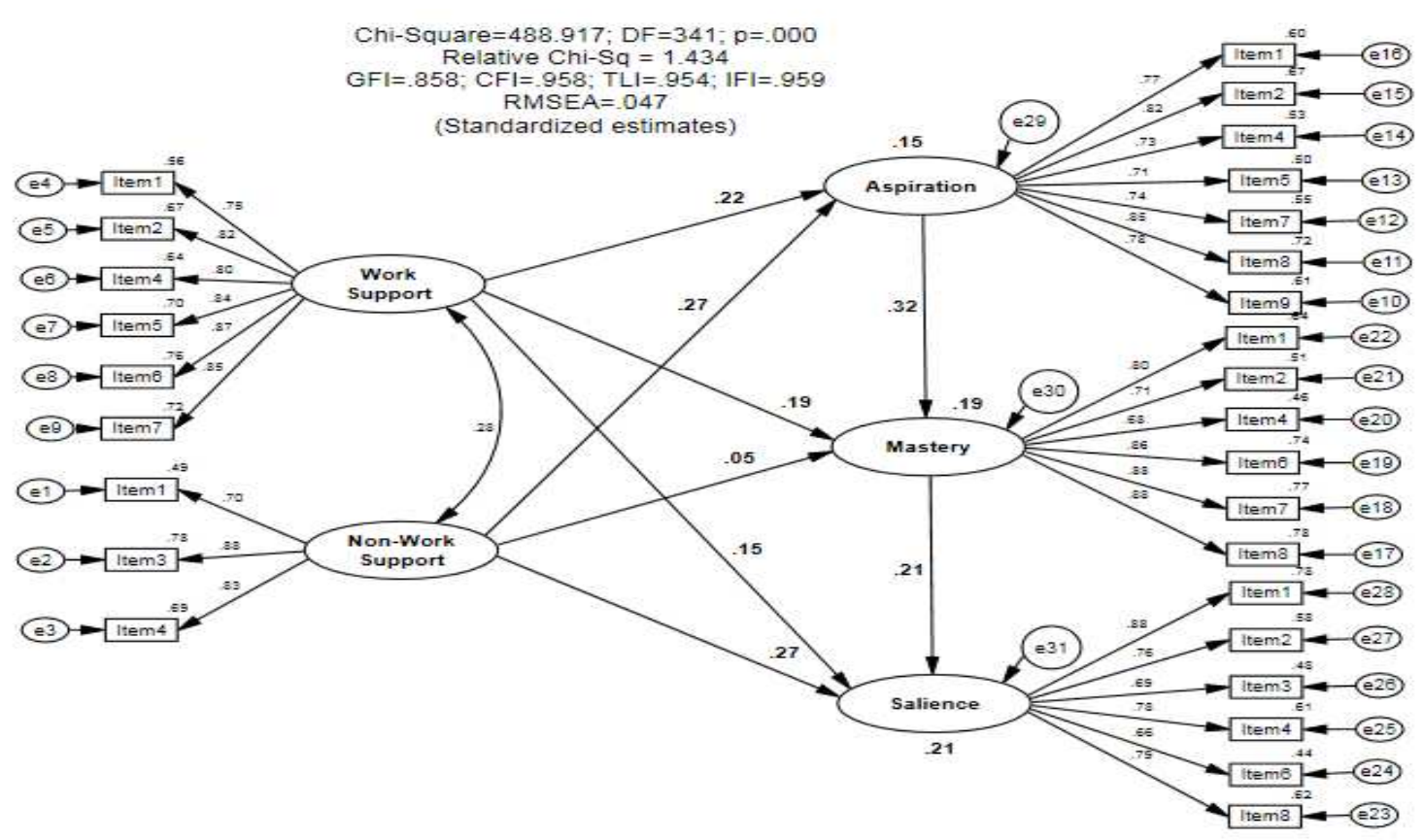

Fig. 2: The structural model with standardized regression weight 
Am. J. Applied Sci., 9 (5): 633-640, 2012

Table 4: Unstandardized and Standardized Regression Weight in Hypothesized Structural Model

\begin{tabular}{|c|c|c|c|c|c|c|c|}
\hline Hypothesized path & & & $\begin{array}{l}\text { Unstandardized } \\
\text { Regression Weights }\end{array}$ & S.E. & $\begin{array}{l}\text { Standardized } \\
\text { Regression Weights }\end{array}$ & C.R. & $\mathrm{P}$ \\
\hline Organizational work support & $\Rightarrow$ & Aspiration & 0.179 & 0.063 & 0.218 & 2.836 & 0.005 \\
\hline Organizational non work support & $\Rightarrow$ & Aspiration & 0.261 & 0.077 & 0.271 & 3.376 & 0.000 \\
\hline Organizational work support & $\Rightarrow$ & Mastery & 0.144 & 0.057 & 0.192 & 2.532 & 0.011 \\
\hline Organizational non work support & $\Rightarrow$ & Mastery & 0.042 & 0.069 & 0.048 & .604 & 0.546 \\
\hline Organizational work support & $\Rightarrow$ & Salience & 0.134 & 0.069 & 0.149 & 1.942 & 0.052 \\
\hline Organizational non work support & $\Rightarrow$ & Salience & 0.289 & 0.083 & 0.275 & 3.499 & 0.000 \\
\hline Aspiration & $\Rightarrow$ & Mastery & 0.290 & 0.074 & 0.319 & 3.944 & 0.000 \\
\hline Mastery & $\Rightarrow$ & Salience & 0.252 & 0.091 & 0.210 & 2.773 & 0.006 \\
\hline
\end{tabular}

Further, there is a significant positive relationship between mastery and salience $(\beta=0.210$, C.R. $=2.773$, $\operatorname{sig}=0.006)$. It means that for any one unit standardized division increases in the aspiration to achieve leadership role, the mastery motive will increase by 0.319. Further, for any one unit standardized division increases in the mastery motive, the salience will increase by 0.210 . Thus, Hypothesis 1 is supported by the data which shows there is a significant path from aspiration to mastery and salience.

$\mathrm{H} 2$ : There is a relationship between organizational work support and three dimensions of achievement motivation in leadership role consist of aspiration, mastery and salience.

The results as indicated in Fig. 2 and Table 4 show that there is a positive significant relationship between organizational work support and aspiration $(\beta=0.218$, C.R. $=2.836$, sig $=0.005$ ) which shows that by any one unit standardized division increases in the organizational work support, aspiration dimension of achievement motivation will increase by .218. The relationship of organizational work support and mastery also is positive significant $(\beta=0.192$, C.R. $=2.532$, sig $=0.011$ ) while there is no significant relationship between organizational work support and salience $(\beta$ $=0.149$, C.R. $=1.942$, sig $=0.052)$. It means that for any one unit standardized division increases in the organizational work support, mastery dimension of achievement motivation will increase by 0.192 while organizational work support could not increase salience in a significant way. Thus, the Hypothesis 2 is supported for the relationships of organizational work support with aspiration and mastery while it is rejected in the case of salience.

H3: There is a relationship between organizational non work support and three dimensions of achievement motivation in leadership role consist of aspiration, mastery and salience.
According to the results as shown in Fig. 2 and Table 4, there is a significant positive relationship between organizational non work support and aspiration $(\beta=0.271$, C.R. $=3.376$, Sig = 0.000) . The relationship of organizational non work support and mastery is not significant $(\beta=0.048$, C.R. $=0.604$, sig $=0.546)$ while there is a significant relationships between organizational non work support and salience $(\beta=.275$, C.R. $=3.499$, sig $=0.000)$. It means that for any one unit standardized division increases in the organizational non work support, aspiration will increase by 0.271 salience will increase by 0.275 while organizational non work support could not increase mastery in a significant way. Thus, Hypothesis 3 is supported for the relationships of organizational non work support with aspiration and salience while it is rejected in the case of mastery.

\section{DISCUSSION}

The conceptualization of achievement motivation focusing on leadership as a competency of extension agents is consistent with the study of Elliot and Dweck (2005) who suggested a need for competence as a primary motivation that assists individuals to adapt to the environment. Further, achievement motivation in leadership role was conceptualized as constituting from aspiration, mastery and salience in accordance with London and Noe's (1997) theory. The results support the underlying theory as there is a significant path among three dimensions of achievement motivation in leadership role from aspiration to mastery and salience. Also the increasing amount of explained variance from aspiration (15\%), to mastery (19\%) salience (21\%) shows that the purposed path is significant.

The supportive strategies of organizations are mostly significant contributors of employee's performance but which kind of support could intensify which kind of behavior. The present study results declare that organizational work support including 
support for the work goal structure attainment along with professionalism, development opportunities and meritocracy are significant contributors to aspiration and mastery dimensions of achievement motivation in leadership role. But most importantly there is a new lesson to learn that it is the organizational non work support which in addition to motivating the employees in aspiration level could support the salience dimension of achievement motivation in leadership role that help the employees to see involvement in leadership role as central to their job life. The organizational non work support refers to family friendly environment that desires a balance between work and family reponsibilities.

\section{CONCLUSION}

The significant path among three dimensions of achievement motivation implied that an extension agent to be motivated to achieve leadership role, first he has to have a desire such as setting a goal then needs to be master the at related competencies of leadership role then needs to see involvement in leadership role as a remarkable role in his career life. It is an important lesson for extension organizations to learn for having motivated employees to achieve leadership role possession of leadership competencies (mastery) is not the only requirement but also aspiration and salience are also important.

The significant relationships of organization work support with aspiration and mastery and significant relationships of organization non work support with aspiration and salience implied that work support stops after aspiring and helping the employees to be master at the role or task and could not motivate them to persist on the task referring to salience dimension of achievement motivation in leadership role. Thus, extension organizations would take a consideration on the importance of work and non work support for achievement of leadership role as a favorable treatment as this would convey positive regards and employees tend to perform better to pay back for the supports given.

Further research could work on the moderating effect of achievement value to see how individual subjective and objective value preference could affect their achievement motivation in leadership role, as the literature supported that the individuals with predominant subjective value more likely prefer non work support while individual with predominant objective value mostly prefer work support.

\section{REFERENCES}

Alderman, M.K., 2007. Motivation for Achievement: Possibilities for Teaching and Learning. 3rd Edn., Routledge, New York, ISBN-10: 0805860487, pp: 343.

Armstrong, M., 2006. A Handbook of Human Resource Management Practice. 10th Edn., Cambridge University Press, London, ISBN-10: 0749446315, pp: 982.

Azril, M.S.H., U. Jegak, M. Asiah, A.N. Azman and A.S. Bahaman et al., 2010. Can quality of work life affect work performance among government agriculture extension officers? A case from Malaysia. J. Soc. Sci., 6: 64-73. DOI: 10.3844/jssp.2010.64.73

Byrne, B.M., 2001. Structural Equation Modeling with AMOS: Basic Concepts, Applications and Programming. 1st Edn., Routledge, London, ISBN10: 0805841040, pp: 352.

Chauhan, J., 2007. Introduction to agricultural extension education in agricultural extension education. RBS College, Bichpuri, India.

Chow, I.H.S., T.W.C. Lo, Z. Sha and J. Hong, 2006. The impact of developmental experience, empowerment and organizational support on catering service staff performance. Int. J. Hospitality Manage., 25: 478-495.

Eisenbergera, R., R. Huntingtona, S. Hutchisonb and D. Sowa, 1985. Perceived organizational support. J. Applied Psychol., 71: 500-507.

Elliot, A.J. and C.S. Dweck, 2005. Handbook of Competence and Motivation. The Guilford Press, New York, ISBN-10: 1593851235, pp: 704.

Farmer, H.S., 1985. Model of career and achievement motivation for women and men. J. Counsel. Psychol., 32: 363-390. DOI: 10.1037/00220167.32.3.363

Farmer, H.S., 1997. Women's andmotivation andrelated andto mastery, career andsalience and andcareer andaspiration: A andmultivariate model andfocusing andon and the effects of andsex androle andsocialization. J. Career Assess., 5: 355-381.

Ferris, D.L., D.J. Brown and D. Heller, 2009. Organizational supports and organizational deviance: The mediating role of organization-based self-esteem. Organ. Behav. Hum. Decision Proc., 108: 279-286. DOI: 10.1016/j.obhdp.2008.09.001

Hochwarter, W.A., C. Kacmar, P.L. Perrewe and D. Johnsonc, 2003. Perceived organizational support as a mediator of the relationship between politics perceptions and work outcomes. J. Vocational Behav., 63: 438-456. DOI: 10.1016/S00018791(02)00048-9 
Hair, J.F., W.C. Black, B.J. Babin and R.E. Anderson, 2010. Multivariate Data Analysis. 7th Edn., Pearson Prentice Hall, United States of America, ISBN-10: 0138132631, ISBN-13: 9780138132637, pp: 785.

Ismail, M. and E.S. Ramly, 2011. Career aspirations of Malaysian research and development professionals in the knowledge economy. J. Eur. Indus. Train., 35: 606-622. DOI: 10.1108/03090591111150121

Karami, R., M. Ismail and R. Sail, 2009. Gender identity on career aspiration to top management among Iranian graduate students of an institution of higher learning. Proceedings of the 1st International Conference on Educational Research and Practice, Jun. 10-11, Malaysia.

Karami, R., M. Ismail and, R.M. Sail, 2011. Gender identity and career aspiration to top management of Malaysian graduate students. Asian Pacific. J. Educ., 31:439-454. DOI: 10.1080/02188791.2011.621653

Kline, R.B., 2008. Promise and pitfalls of structural equation modeling in gifted research. American Psychological Association Books, Washington, DC.

Lapierre, L.M., P.E. Spector, T.D. Allen, S. Poelmans and C.L. Cooper et al., 2008. Family-supportive organization perceptions, multiple dimensions of work-family conflict and employee satisfaction: A test of model across five samples. J. Vocational Behav., 73: 92-106. DOI: 10.1016/j.jvb.2008.02.001
Leal, V.M., 2006. Predictors of non-traditional career self-efficacy in Mexican American adolescent women. The Ohio State University, USA.

London, M. and R.A. Noe, 1997. London's career motivation theory: An update on measurement and research. J. Career Assess., 5: 61-80. DOI: 10.1177/106907279700500105

Ogden, S.M., D. McTavish and L. McKean, 2006. Clearing the way for gender balance in the management of the UK financial services industry: Enablers and barriers. Women Manage. Rev., 21: 40-53. DOI: $10.1108 / 09649420610643402$

Schumacker, R.E. and R.G. Lomax, 2004. A Beginner's Guide to Structural Equation Modeling. 2nd Edn., Routledge, New Jersey, London, ISBN-10: 0805840184, pp: 498.

Suthar, V. and R.A. Tarmizi, 2010. Effects of students' beliefs on mathematics and achievement of university students: regression analysis approach. J. Soc. Sci., 6, 2: 146-152. DOI: 10.3844/jssp.2006.146.152

Sweenet, K., 2004. The Relationship between Family Commitment and Career Salience among Coaches of elite NCAA Division I-A Women's Programs. 1st Edn., University of New Mexico, New Mexico, pp: 210 . 